\title{
Mechanical and dielectric properties at liquid nitrogen temperature of epoxy/AIN composites modified with different contents of flexible amine
}

\author{
Zhuhua Zhao ${ }^{1} \cdot$ Xiaofeng Zou $^{1} \cdot$ Ju Wang $^{1} \cdot$ Xuan Yu$^{1} \cdot$ Feng Yang $^{1} \cdot$ Zhou Yu $^{1} \cdot$ Hong Zhang $^{1} \cdot$ Yong Zhao $^{1,2}$. \\ Yong Zhang ${ }^{1}$ (D)
}

Received: 31 January 2020 / Accepted: 15 April 2020 / Published online: 27 April 2020

(c) Springer Nature Switzerland AG 2020

\begin{abstract}
Epoxy resin has been wide applied in aerospace, superconducting industries because of the high electrical insulation, excellent adhesive properties and great chemical resistance. In this paper, epoxy/AIN composites were prepared by changing the content of the flexible amine (D-230) and the diethyl toluene diamine (DETDA) from 0 to $100 \mathrm{wt} \%$. The effects of different ratios of D-230 and DETDA were investigated on the mechanical and dielectric properties of epoxy/ AIN composites at liquid nitrogen temperature $(77 \mathrm{~K})$ and room temperature (RT). The properties of the samples were characterized by flourier transformed infrared (FTIR), scanning electron microscopy and broadband dielectric spectrometer. FTIR results showed that AIN particles were successfully modified by the silane coupling agent (KH-560). Tensile testing showed that the addition of flexible diamines generally improved the elongation at break at both RT and $77 \mathrm{~K}$ and the tensile strength at $77 \mathrm{~K}$. The introduction of D-230 led to a lower dielectric constant at cryogenic temperature than that at RT.
\end{abstract}

Keywords Epoxy/AIN composites · Mechanical property · Dielectric property · Cryogenic temperature

\section{Introduction}

The development of superconducting cryogenic temperature technology has brought extensive application of composite materials at cryogenic temperature. In recent years, many resistant epoxy resins have been used as binders and impregnating materials for cryogenic temperature applications [1-3]. Therefore, the research on the performance of epoxy resin under ultra-low temperature is gradually attracting many attentions [4-8]. Figure 1 is the molecular formula of epoxy resin E-51, showing that epoxy resin molecules contain a large number of extremely active epoxy groups, ether bonds and hydroxyl groups [9]. They can produce chemical bond or adsorption between molecules, and cross-link with curing agents, so epoxy resin has high bonding strength and good moisture resistance as adhesive.

In recent years, polymer composites have been widely used in the field of electronic devices, including central processing units, high-integrated memory chips, batteries, displays and electronic packaging materials for their excellent adhesive properties, good electrical insulation behaviors, low cost, high electrical insulating characteristics, great chemical resistance [10-14]. However, epoxy resins also have disadvantages such as brittleness, low toughness, and poor impact resistance, which limit the wide application. Incorporating heat-conducting insulating inorganic particles into epoxy resins can improve the

$\triangle$ Yong Zhao, yzhao@swjtu.edu.cn; $\varangle$ Yong Zhang, yongzhang@swjtu.edu.cn | ${ }^{1}$ Key Laboratory of Advanced Technologies of Materials (Ministry of Education of China), and Superconductivity and New Energy R\&D Center, Southwest Jiaotong University, Chengdu 610031, China. ${ }^{2}$ College of Physics and Energy, Fujian Normal University, Fuzhou 350117, China. 


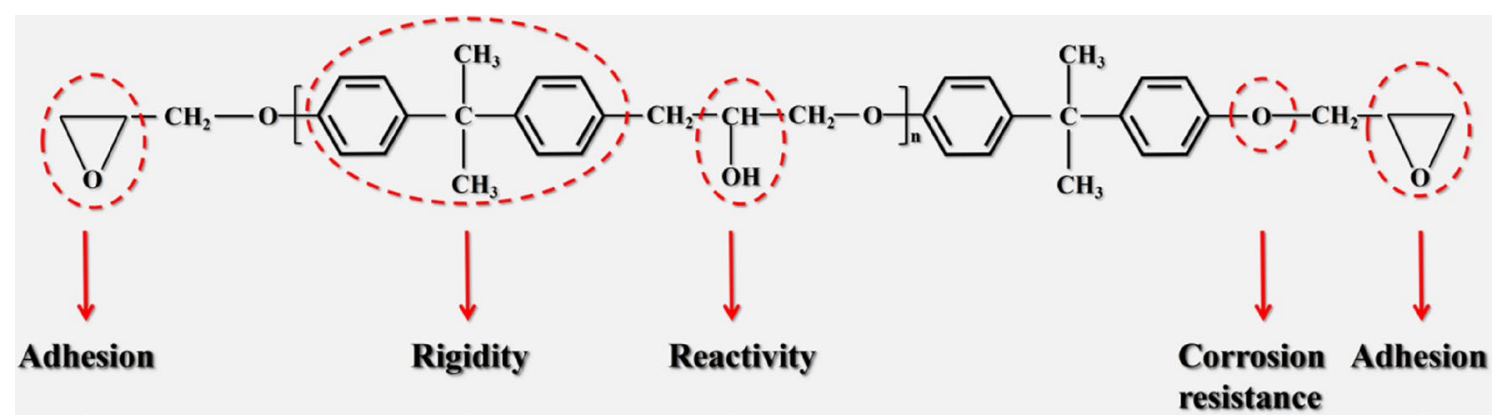

Fig. 1 Molecular formula and properties of epoxy resin

thermal conductivity and preserve the electrical insulation properties $[15,16]$. Various kinds of fillers, such as metals and metal oxides [17] aluminum nitride (AIN) [18-20], boron nitride [21], and silicon carbide [22] have been applied to prepare thermally conductive polymer composites. In this paper, AIN is used as fillers to prepare epoxy/ AIN composites. AIN is a diamond-like nitride with high intrinsic thermal conductivity $(319 \mathrm{~W} / \mathrm{mK})$ [23], high electrical resistivity $\left(>10^{14} \Omega \mathrm{cm}\right.$ ) [24], low thermal expansion coefficient (theoretical value: $4.4 \mathrm{ppm} /{ }^{\circ} \mathrm{C}$ ) [25], and low dielectric constant (8.9 at $1 \mathrm{MHz}$ ) [24]. However, due to the high surface energy, AIN is extremely easy to agglomerate into large particles and could not be uniformly dispersed in the epoxy resin matrix. Functional modification of organic molecules on the surface of AIN particles provides a feasible way to improve their dispersion in epoxy groups. The modification with functionalized organic molecules not only improves the compatibility of AIN particles with the resin matrix, but also enhances the interfacial force between AIN particles and the matrix, thereby obtaining high-performance epoxy/AIN composites.

In comparison with the researches that have been carried out on the mechanical and dielectric properties of the epoxy/AIN composites. Yang et al. [26] investigated the mechanical properties of modified epoxy resins with flexible diamines at different temperatures from $77 \mathrm{k}$ to RT. In their study, diethyl toluene diamine (DETD) cured DGEBA epoxy resin has been modified by two flexible diamines (D-230 and D-400). The results show that the addition of flexible diamines generally improves the elongation at break and impact strength at both RT and $77 \mathrm{~K}$. Chia-Ching et al. [27] investigated the dielectric properties of epoxy/ AIN composites. The effects of the content of AIN filler on the physical and dielectric properties of epoxy/AIN composites are developed. They found that as the content of AIN powder in the epoxy/AIN composites increases from 5 to $40 \mathrm{wt} \%$, the dielectric constant increases from 6.52 to 7.28 (measured at $1 \mathrm{MHz}$ ). The loss tangent of epoxy/ AIN composites is slightly increased as the measured frequency increases. Zhu et al. [28] investigated dielectric properties of immiscible LDPE/epoxy blend filled with hybrid filler consisting of HGM and nitride particle. In their study, they found that the dielectric properties of the HGM and nitride powders filled composites with an immiscible LDPE/epoxy blend matrix depend on the volume ratio of LDPE to epoxy. With increase in the volume ratio of LDPE to epoxy, the $D_{k}$ continually decreases, and the $D_{f}$ first decreases then increases. At a volume ratio of LDPE to epoxy of 3:7, the composite shows an optimum combination of dielectric properties.

In this work, a novel method for epoxy/AIN composites preparation was investigated, and the effects of different ratios of flexible amine (D-230) and diethyl toluene diamine (DETDA) were studied on the mechanical and dielectric properties of epoxy/AIN composites at liquid nitrogen temperature $(77 \mathrm{~K})$ and room temperature $(\mathrm{RT})$. It was found that by changing the content of D-230, composites could be obtained with better mechanical and dielectric properties at $77 \mathrm{~K}$ than $\mathrm{RT}$, which laid a foundation for the application of epoxy resin at cryogenic temperature.

\section{Experimental}

\subsection{Materials}

AIN with an average diameter of $500 \mathrm{~nm}$ was obtained from Hefei Kaier Nanometer Technology Development Co. Ltd (China). Bisphenol A epoxy resin (E-51) and the cycloaliphatic epoxy resin were purchased from Shandong Usolf chemical technology Co. Ltd (China). The D-230 and the DETDA were used as harder and purchased from Chengdu Yuanda Chemical Co. Ltd (China). The mass ratios of resin, hardener and AIN were kept at 10:3:2. The addition amount of AIN nanopaticles remained consistent across all samples. 


\subsection{Preparation of epoxy/AIN composites}

Surface modification of AIN nanoparticles was performed by using a wet method according to previous report [29]. Briefly, AIN and $\mathrm{KH}-560$ (mass ratio 1:20) were dispersed in acetone, magnetically stirred for $2 \mathrm{~h}$, ultrasonically dispersed for $1 \mathrm{~h}$, washed and placed in a vacuum oven at $80^{\circ} \mathrm{C}$ for $24 \mathrm{~h}$.

The epoxy/AIN composites were prepared by preheating E-51 and cycloaliphatic epoxy resin in an oven at $60{ }^{\circ} \mathrm{C}$ for $0.5 \mathrm{~h}$ to reduce the viscosity, followed by adding AIN particles under continuous stirring to obtain homogeneous mixtures. Then D-230 and DETDA in different ratios were mixed under magnetic stirring for $2 \mathrm{~h}$, ultrasonic dispersion for $1 \mathrm{~h}$ and vacuum defoaming, followed by pouring into a mold for curing. Tensile specimens were prepared according to ASTM D638-96 standards. The dimensions of impact specimens are $4 \mathrm{~mm} \times 10 \mathrm{~mm} \times 80 \mathrm{~mm}$ with a $0.2 \mathrm{~mm}$ v-notch. The curing process was performed according to $80^{\circ} \mathrm{C} / 20 \mathrm{~h}$ and $130^{\circ} \mathrm{C} / 10 \mathrm{~h}$, then the molds were left in the oven and cooled gradually to room temperature.

\subsection{Characterization}

The flourier transformed infrared (FTIR) spectrum of AIN particles was obtained using a Paragon 1000 (Perkin Elmer Inc., USA) with the scanning range from 4000 to $500 \mathrm{~cm}^{-1}$.

The tensile properties were tested using a tensile testing machine (Reger Instruments Ltd., China) under tensile rates of $5 \mathrm{~mm} / \mathrm{min}$ at RT and $2 \mathrm{~mm} / \mathrm{min}$ at $77 \mathrm{~K}$. The testing at $77 \mathrm{~K}$ was performed within seconds after the specimens were dipped in a liquid nitrogen filled cryostat for $20 \mathrm{~min}$. The tensile strength was calculated based on Eq. (1):

$\sigma=\frac{p}{b \times d}$

where $\sigma$ was the tensile strength (MPa), $p$ was maximum load on specimen $(\mathrm{N}), b$ was sample width $(\mathrm{mm})$, and $d$ was sample thickness $(\mathrm{mm})$, respectively.

The impact strength of the samples was measured with a REGER Impact Tester, and the test was according to ASTM $D-256$. The dimensions of the samples for impact test were $4 \mathrm{~mm} \times 10 \mathrm{~mm} \times 80 \mathrm{~mm}$ with a $0.2 \mathrm{~mm}$ v-notch. Impact test at $77 \mathrm{~K}$ was performed with the specimens dipped in a cryostat filled with liquid nitrogen for $20 \mathrm{~min}$, and the test was completed in seconds after taking the specimens out of the cryostat. At least three specimens were tested for each composition. The tensile strength was calculated based on Eq. ((2)):
$A_{k}=\frac{E_{c}}{b \times d} \times 10^{3}$

where $A_{k}$ was the impact strength $\left(\mathrm{KJ} / \mathrm{m}^{2}\right), E_{c}$ was fracture absorption energy $(\mathrm{J}), b$ was sample width $(\mathrm{mm})$, and $d$ was sample thickness $(\mathrm{mm})$, respectively.

A field emission scanning electron microscope (FE-SEM, JSM-7800F, Japan) was used to observe the tensile fracture section of epoxy/AIN composites. For SEM observation, the fractured surface was sputtered with thin layers of gold to avoid the accumulation of charge.

The dielectric properties were tested on a broadband dielectric spectrometer (Novocontrol Concept 80, Germany) with a test frequency range of $10^{1}-10^{7} \mathrm{~Hz}$. The sample was placed in the middle of two circular electrodes with a diameter of $10 \mathrm{~mm}$, and a voltage of $1 \mathrm{~V}$ was applied to both surfaces of the sample. Before the test, the samples were divided into two groups. One group was the control group. The two sides of the samples were uniformly coated with a layer of silver paste, then placed in an vacuum oven for $12 \mathrm{~h}$. Another group was the experimental group. First, the samples were placed in liquid nitrogen for $30 \mathrm{~min}$. Then, the other steps were same as the control group. The control group was named as the dielectric constant of the epoxy/AIN composites with different D-230 content at RT. The experimental sample was named as the dielectric constant of the epoxy/AIN composites with different D-230 content at $77 \mathrm{~K}$. The dielectric properties of the samples after liquid nitrogen treatment were analyzed.

\section{Results and discussion}

\subsection{Modification of AIN particles}

The FTIR spectrum of as received AIN and $\mathrm{KH}-560$ treated AIN are shown in Fig. 2. The FTIR spectra were substantially similar for AIN after modification by $5 \mathrm{wt} \%$ and 6 wt\% KH-560. As shown in Fig. 2, the strong absorption at $3430 \mathrm{~cm}^{-1}$ was attributed to hydroxyl group $(-\mathrm{OH})$ stretching, and that at $1631 \mathrm{~cm}^{-1}$ was attributed to $-\mathrm{NH}$ - group vibration. It was indicated that AIN particles had higher affinity and reactivity to moisture and water [30]. The peak at $740 \mathrm{~cm}^{-1}$ was ascribed to the characteristic absorption peak of AIN. At the same time, new absorption peaks at 2921, 2854, and $1040 \mathrm{~cm}^{-1}$ and those at 2921 and $2854 \mathrm{~cm}^{-1}$ were characteristic of asymmetric and symmetric $-\mathrm{CH}_{2}$ stretching vibrations, respectively. The peak at $1040 \mathrm{~cm}^{-1}$ was contributed to $\mathrm{Si}-\mathrm{O}$ stretching vibration. The changes in the infrared absorption spectra of the raw AIN particles and $\mathrm{KH}-560$-treated AIN particles indicated that the surface of AIN particles was successfully grafted with silane coupling agents. 
Figure 3 is the schematic representation of reaction among AIN, KH-560, and epoxy resins. After surface treatment of AIN by $\mathrm{KH}-560$, there is better interfacial compatibility between treated AIN and resin matrix, which is beneficial for enhancing the interface adhesion strength of epoxy/AIN composites [31]. Furthermore, the surface treatment of AIN can improve the uniform dispersion of AIN in resin matrix, which finally increases the mechanical properties of the composites.

Mechanical properties of epoxy/AIN composites.

Figure 4a shows the tensile strength of epoxy/AIN composites at $\mathrm{RT}$ and $77 \mathrm{~K}$. The tensile strength under $77 \mathrm{~K}$ was
Fig. 2 a FT-IR spectra of as received AIN and $\mathbf{b}$ AIN after modification with $5 \mathrm{wt} \%$ and c 6 wt $\% \mathrm{KH}-560$ and molecular formula of silane coupling agent $\mathrm{KH}-560$

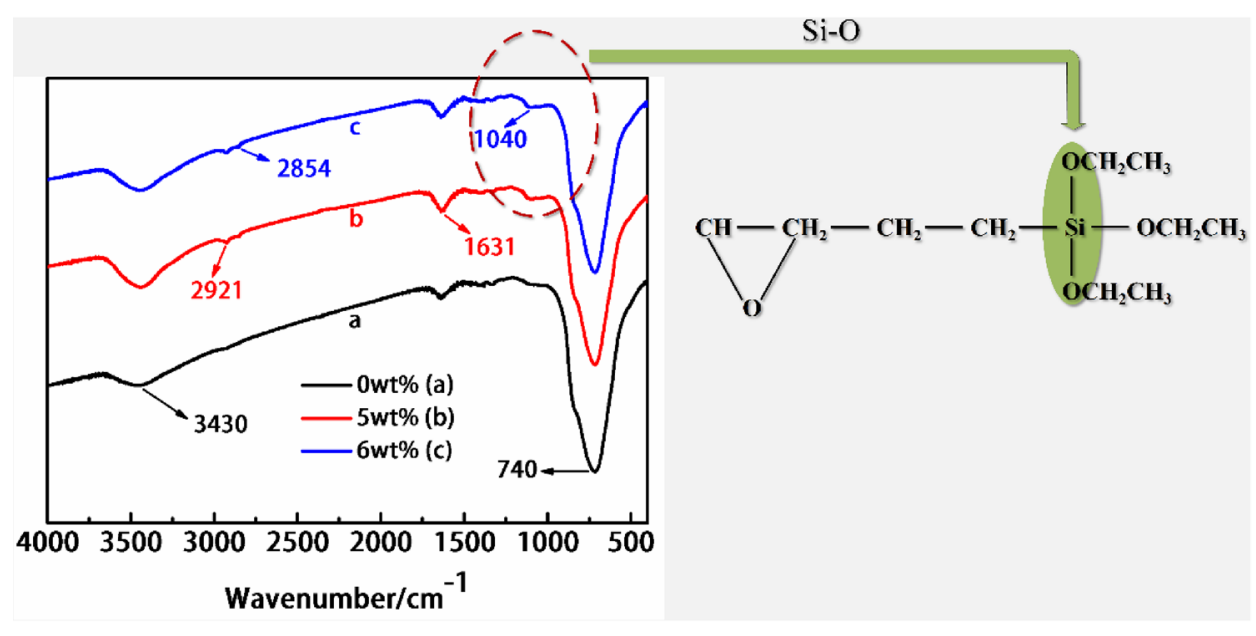

Fig. 3 Schematic representation of reaction among AIN, $\mathrm{KH}-560$, and $\mathrm{E}-51$

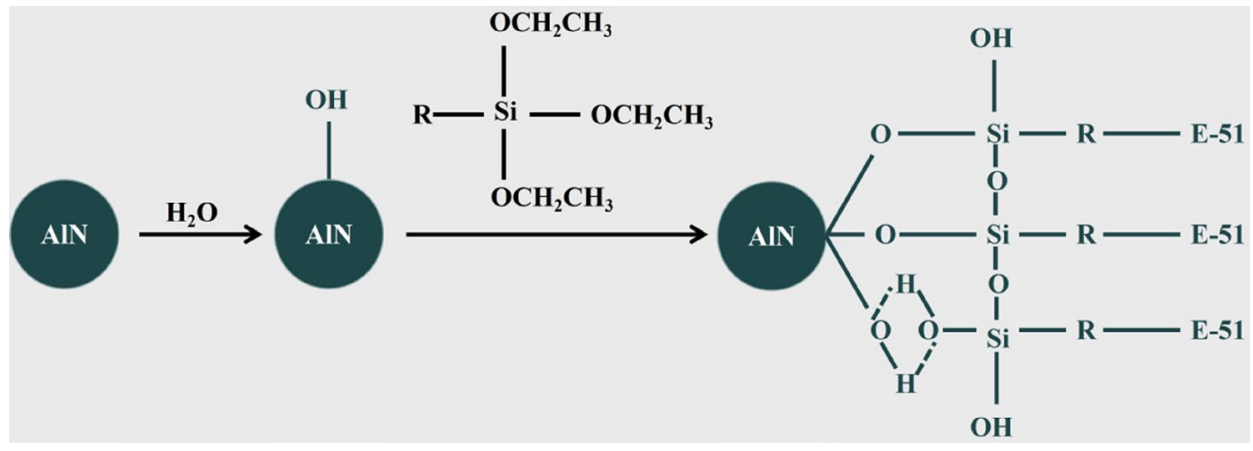

(a)
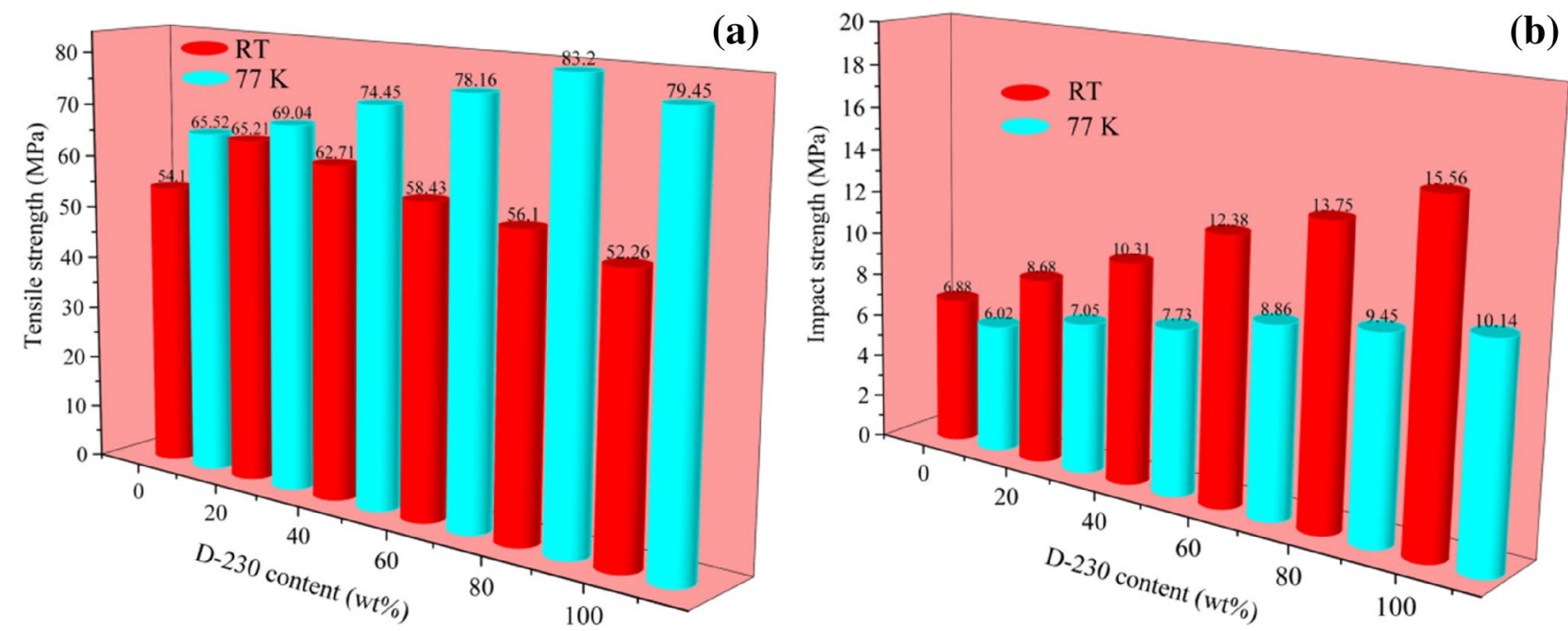

Fig. 4 a Tensile strength and $\mathbf{b}$ impact strength of epoxy/AIN composites with different D-230 contents at RT and $77 \mathrm{~K}$ 
higher than that at RT. When the D-230 content was 80 $w t \%$, the tensile strength of the epoxy/AIN composites at $77 \mathrm{~K}$ was $83.2 \mathrm{MPa}$, which was $48.3 \%$ higher than that containing $80 \mathrm{wt} \%$ of D-230 at RT.

When the filling amount of D-230 was less than 20 $w t \%$, the tensile strength of composites increased with the increase of D-230 content at RT. When the addition amount of D-230 was $20 \mathrm{wt} \%$, the epoxy/AIN composites had the highest tensile strength at RT. As the D-230 content increased further, the tensile strength of the composites began to decrease. In general, the addition of soft matters like rubber and polyurethane to epoxy resins resulted in reductions of the tensile strength at RT [32]. The solidification of the epoxy/AIN composites at high temperatures produced internal stress, resulted from the bulk shrinkage from high temperature to room temperature during the cooling process. Due to the internal stress, micro-cracks and voids were generated inside the composites, which greatly affected the performance of the final product. Conversely, the introduction of soft segments like D-230 into brittle epoxy can significantly reduce the internal stress $[26,33]$. When a proper amount of D-230 was added, the internal stress of the sample was reduced, and the crack resistance of the system was improved, so that the tensile strength was increased by adding an appropriate amount of D-230. On the other hand, as the content of the flexible diamine increased, the crosslink density of the system decreased, thereby lowering the cohesive strength, so the tensile strength decreased as the relative content of D-230 increased.

When the addition content of D-230 increased from 0 to $80 \mathrm{wt} \%$, the tensile strength of the composites at $77 \mathrm{~K}$ increased with increasing the D-230 content. When the addition amount was $80 \mathrm{wt} \%$, the epoxy/AIN composites had the highest tensile strength at $77 \mathrm{~K}$. The higher tensile strength of epoxy resin composites at $77 \mathrm{~K}$ was resulted from the increased cohesive strength caused by the cold shrinkage of the chemical bond and the network structure. The pure diethyl toluene diamine curing system frozen and became more brittle at $77 \mathrm{~K}$, while D-230 was free to move at cryogenic temperatures due to the rotatability of the ether bond [26]. The spacing between molecular chains became smaller, and the molecular chain arrangement became denser. The anti-cracking ability of the system increased, so the tensile strength of the composites containing D-230 were larger than that of pure DETDA system at $77 \mathrm{~K}$, and the contribution to the tensile strength increased with the increase of the content of the flexible component. When the D-230 content was $100 \mathrm{wt} \%$, the tensile properties of the composites were slightly decreased.

Figure $4 \mathrm{~b}$ shows the impact strength of epoxy/AIN composites at RT and $77 \mathrm{~K}$. In general, the impact strength increased with increasing D-230 content at RT and $77 \mathrm{~K}$. At RT, the increased impact strength can be attributed to the reduction of internal stress due to the stress relaxation by flexible molecular chains of flexible diamines D-230. At $77 \mathrm{~K}$, ether linkages in D-230 could still be flexible via changing the main chain bond angles since they could undergo deformation at cryogenic temperature. Therefore, as the content of D-230 increased, the impact strength of the epoxy/AIN composites gradually increased at $77 \mathrm{~K}$.

Figure 5 represents the curing network structures of unmodified and D-230 modified epoxy resins. There

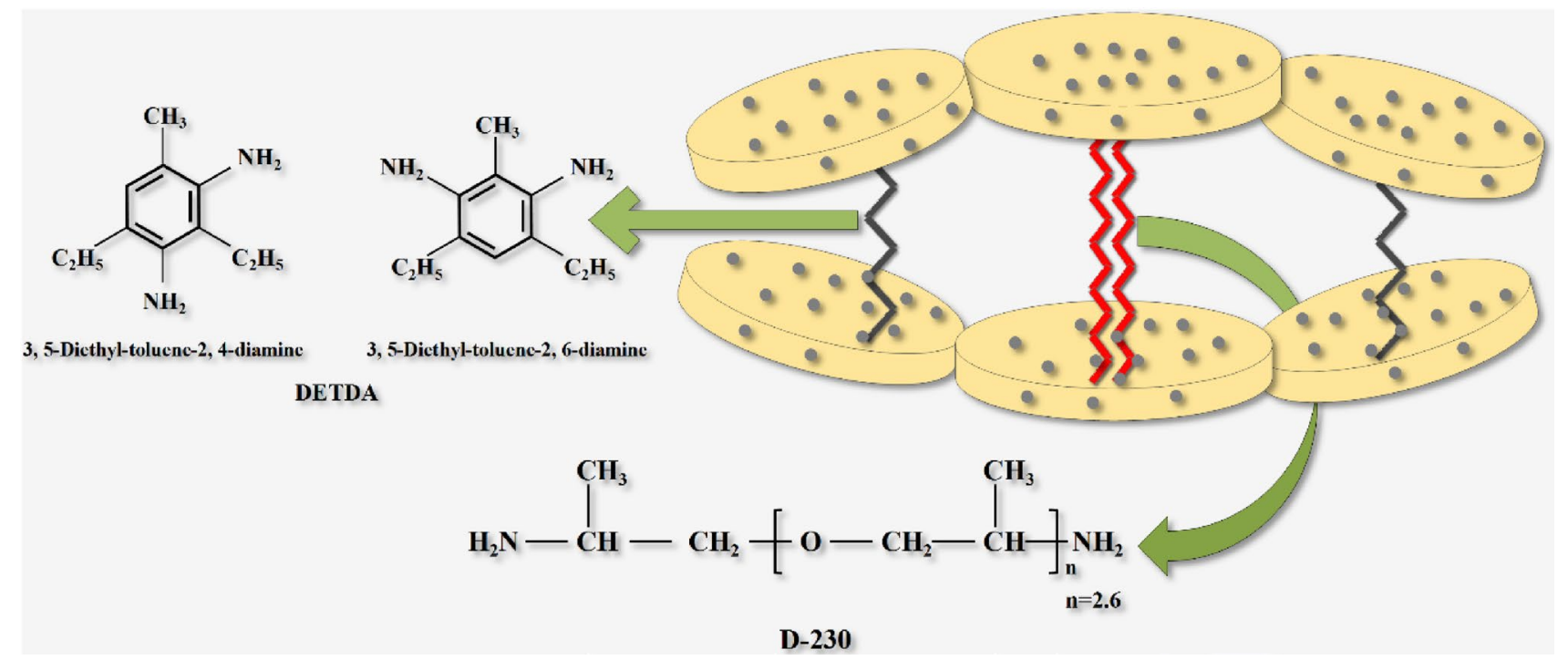

Fig. 5 Schematic representation of curing network structures of D-230 modified epoxy resin system and molecular formula of DETDA and D-230 
was more space between the D-230 modified epoxy/ AIN composites, leading to a decrease in the network structure density. Therefore, after adding more D-230, there was more space between the composites, so the tensile strength tended to decrease. As shown in Fig. 5, the difference in chain length between the two curing agents would promote the mobility of the macromolecule to a certain extent. In other words, the DETDA and the D-230 had a better synergistic effect in improving the toughness of epoxy/AIN composites compared to pure DETDA. In addition, the tensile strength at $77 \mathrm{~K}$ was much higher than the tensile strength at RT, but the tensile strain at $77 \mathrm{~K}$ was much lower than that at RT, due to the uppressed macro-molecular mobility at $77 \mathrm{~K}$.

SEM observation.

Figure 6 shows the morphology of the fractured surfaces for the epoxy/AIN composites used for tensile experiments. The fractured paths of river line patterns could be observed, indicating a brittle fracture. As shown in the Fig. $6 b$ and $d$, most of the nanoparticles were embedded in the epoxy matrix, indicating good compatibility and interfacial bonding between AIN and epoxy resin.

In the pure diethyl toluene diamine curing system, the crack tip of the tensile section at $77 \mathrm{~K}$ and RT continued to expand until fracture and without crack termination, and presented a typical brittle fracture morphology. The fracture morphology at $77 \mathrm{~K}$ was smoother than that at $\mathrm{RT}$, indicating that the brittleness at $77 \mathrm{~K}$ was greater than that at RT. Meanwhile, surface-modified AIN nanoparticles could improve the interaction of two-phase interfaces. The particle size of AIN was small and uniformly dispersed in the resin matrix. In addition, there were many chemical bonds on the AIN surface, which could easily interact with the resin molecules to form stronger interfacial bonds. Thus, when subjected to impact, more silver streaks and plastic deformation would be produced to absorb energy.

Dielectric properties of epoxy/AIN composites.

Figure $7 \mathrm{a}$ and $\mathrm{b}$ show the frequency dependence of the dielectric constant of epoxy/AIN composites. The dielectric properties of composites after liquid nitrogen treatment were analyzed. The dielectric constant of the
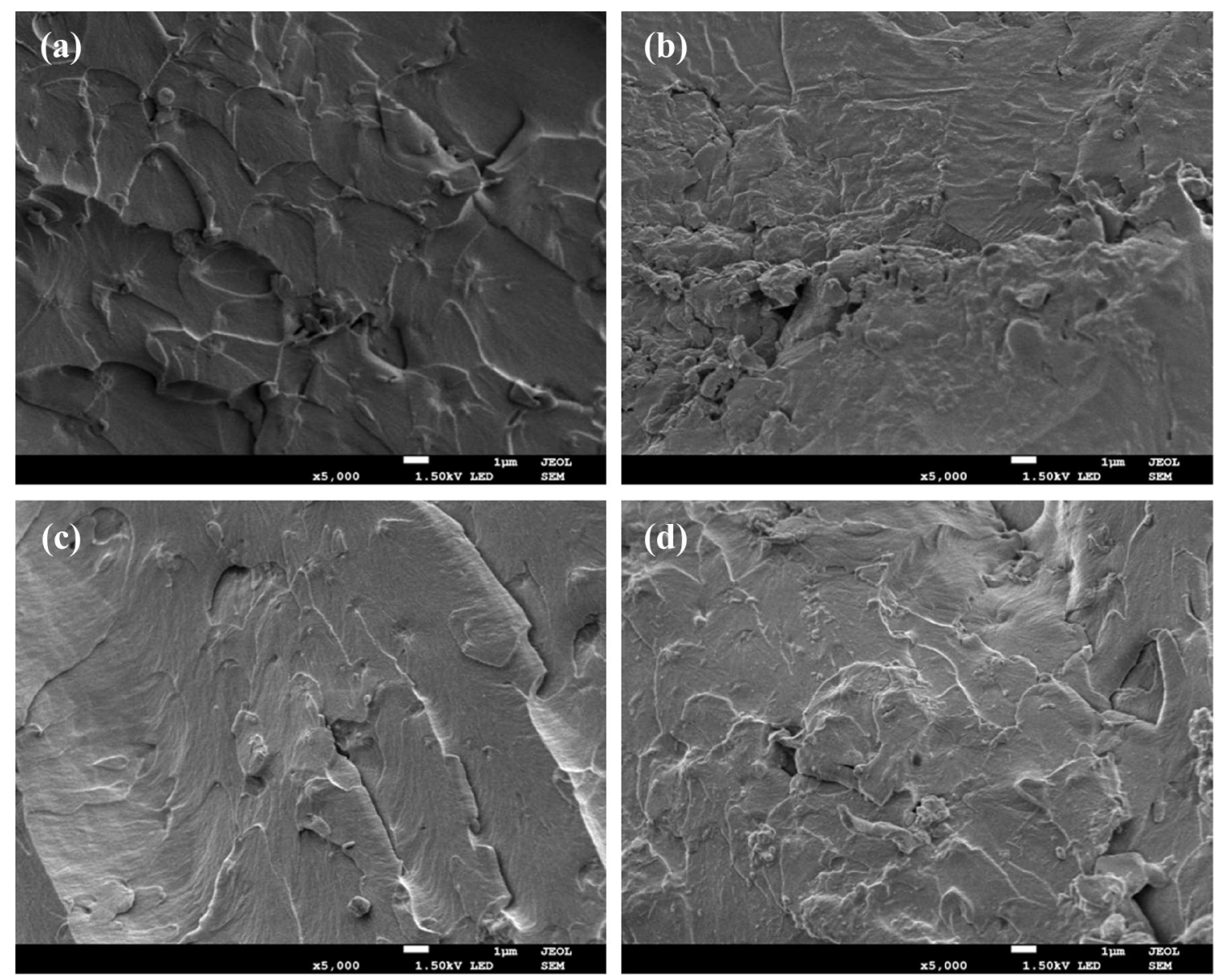

Fig. 6 a SEM images $(\times 5000)$ of epoxy/AIN composites without D-230 at RT and b $77 \mathrm{~K}$ and $\mathbf{c}$ composites containing 80 wt\% D-230 at RT and $\mathbf{d} 77 \mathrm{~K}$

\section{SN Applied Sciences}


(a)

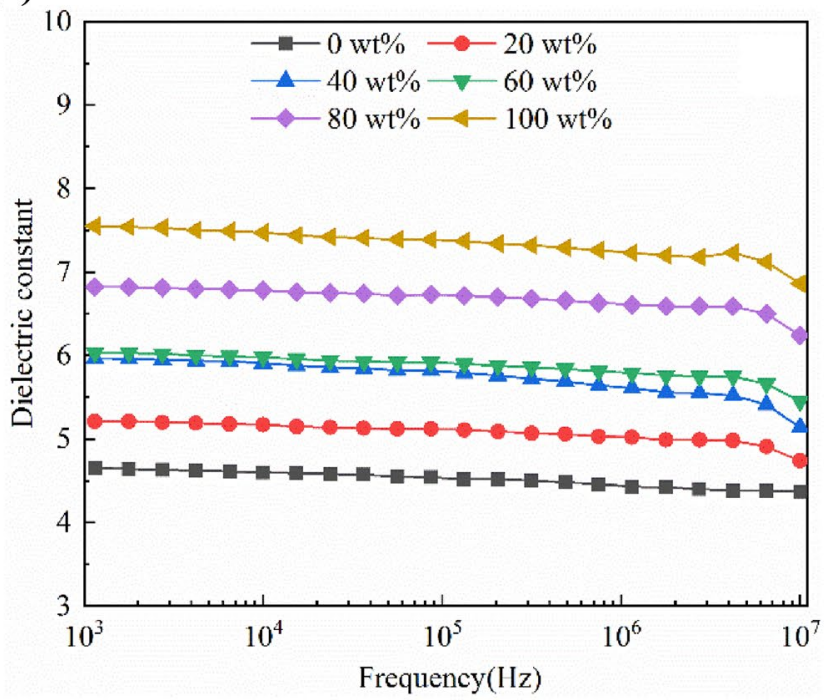

(b)

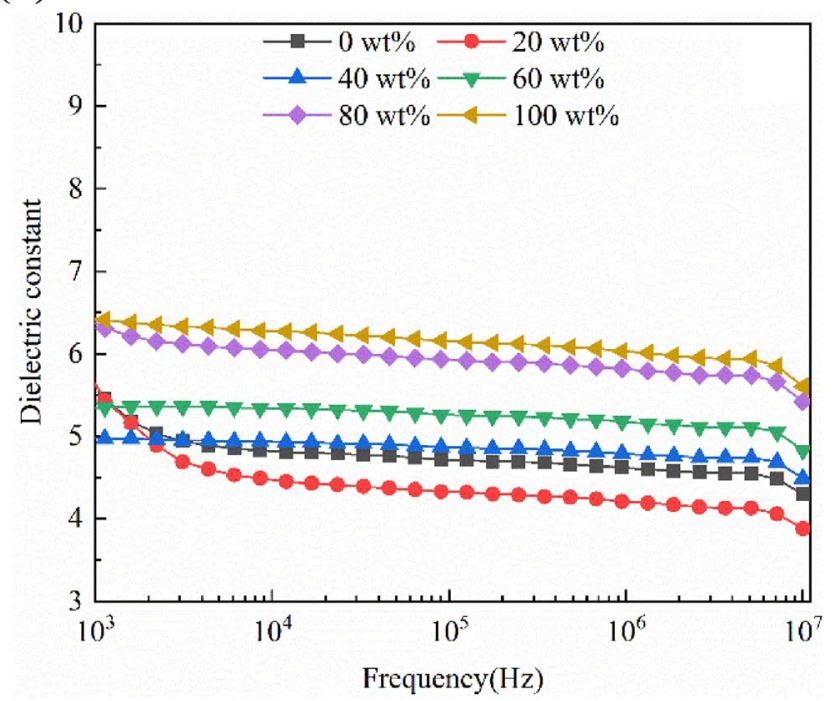

Fig. 7 Frequency dependence of dielectric constant for epoxy/AIN composites containing different D-230 content at a RT and b $77 \mathrm{~K}$

epoxy/AIN composites slightly decreased with increasing the frequency, and the introduction of D-230 led to a slight increase in the dielectric constant. With the introduction of D-230, the dielectric constant at $77 \mathrm{~K}$ was lower than that at RT.

When the polymer was filled with an inorganic filler, the dielectric constant generally increased because of the higher dielectric constant of fillers by nature than the polymer matrix and interfacial polarization [23]. In this paper, the content of D-230 in all samples was same, so the different dielectric constant of the composites was due to the interfacial polarization effect. The polarization appeared in heterogeneous media consisting of phases with different dielectric permittivity, attributed to the accumulation of charges at the interfaces [34]. The dielectric constant of epoxy/AIN composites was closely associated with the dipolar polarization. Here, D-230 was introduced to reduce the rigidity of the epoxy resin, which could promote the dipolar movement and enhanced the orientation polarization and thus resulting in higher dielectric constants. At low frequencies, all the free dipole groups in the epoxy molecular chains could orient themselves, resulting in higher dielectric constant at these frequencies. As the electric field frequency increased, the polarization failed to settle itself completely. The contributions of these dipole groups to the dielectric constant was continuously reduced, resulting in a decrease in the permittivity of the epoxy system at higher frequencies, so the dielectric constant of epoxy resin dropped approaching at high frequencies [35]. The composites had a lower dielectric constant at $77 \mathrm{~K}$ with the same content of D-230 because the dipolar movement and the orientation polarization were limited at $77 \mathrm{~K}$.

As shown in Fig. 8a and b, the dielectric loss tangent exhibited initially slight decreases with increasing the frequency, followed by an increase to a certain frequency of $10^{7} \mathrm{~Hz}$. The addition of D-230 caused a slight increase in dielectric loss tangent. The dielectric loss values of all samples were less than 0.04 , indicating great dielectric properties.

Dielectric loss depended on the electrical conductivity in the epoxy composites. The electrical conductivity in turn depended on the number of charge carriers in the bulk of the material, the relaxation time of the charge carriers and the frequency of the applied electric field [35]. The increase in the value of dielectric loss tangent could be attributed to dipole polarization, since dipoles had less time to orient themselves in the direction of the alternating field with increasing frequency. So, the dipole polarization effects reduced when the frequency increased further, and the value of the dissipation factor declined accordingly. Furthermore, the decrease in dielectric loss at low frequency also can be ascribed to the dc conductivity. However, the dielectric loss tangent tended to increase further, which was an obvious relaxation loss process related to the epoxy resin. Because AIN particles were well dispersed in the matrix, the composites revealed a lower loss tangent. The dipolar polarization motion was frozen at $77 \mathrm{~K}$, so the dielectric constant and the dielectric loss constant of the epoxy/AIN composites after liquid nitrogen treatment were reduced, indicating that the composites had better dielectric properties at cryogenic temperature, which laid 

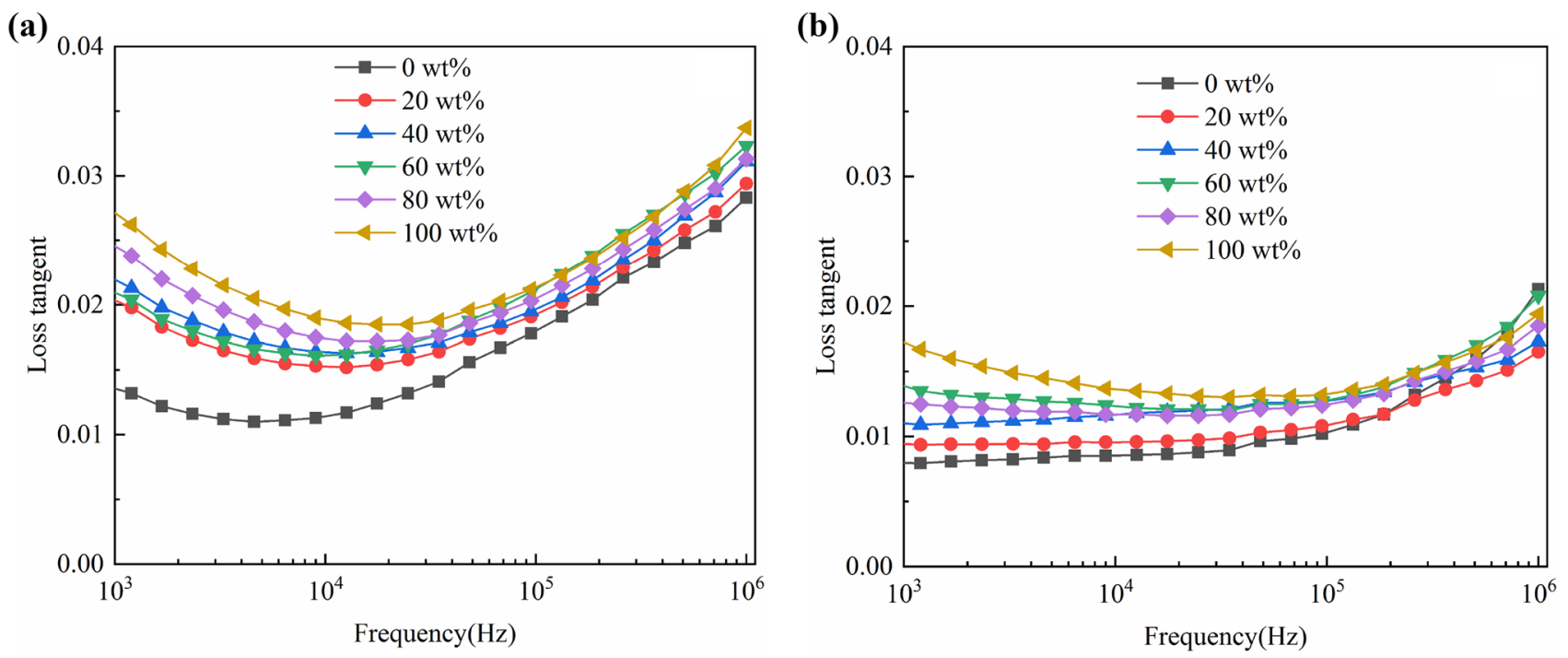

Fig. 8 Frequency dependence of dielectric loss constant for epoxy/AIN composites containing different D-230 content at a RT and b $77 \mathrm{~K}$

a foundation for the application of epoxy resin in the field of cryogenic temperature and insulation.

\section{Conclusions}

The cryogenic tensile strength increased with the increasing flexible diamine content except the D-230 content of $100 \mathrm{wt} \%$. When the D- 230 content was $80 \mathrm{wt} \%$, the tensile strength of the epoxy/AIN composites at $77 \mathrm{~K}$ was 83.2 $\mathrm{MPa}$, which was $48.3 \%$ higher than that containing the same content of D-230 at RT. The impact strength increased with increasing D-230 content at RT and $77 \mathrm{~K}$. The dielectric constant and dielectric loss of the epoxy/AIN composites increased slightly with increasing the D-230 contents, but it still remained at a low level. With the introduction of D-230, the dielectric constant of the composites at $77 \mathrm{~K}$ was lower than that at RT. The dielectric losses at both $\mathrm{RT}$ and $77 \mathrm{~K}$ were less than 0.04 , indicating that the obtained composites had excellent dielectric properties. In conclusion, when the D-230 content was $80 \mathrm{wt} \%$, epoxy/ AIN composites could be obtained with better mechanical and dielectric properties at $77 \mathrm{~K}$.

Acknowledgements The authors are grateful for the financial support of the National Key Research and Development Plan (Grant No. 2017YFE0301401), the Funds of Science and Technology Department of Sichuan Province (Grant Nos. 2017JY0057, 2018JY0003).

\section{Compliance with ethical standards}

Conflict of interest The authors declare that they have no conflict of interest.

\section{SN Applied Sciences}

\section{References}

1. Jin FL, Li X, Park SJ (2015) Synthesis and application of epoxy resins: a review. J Ind Eng Chem 29:1-11

2. He Y, Chen Q, Yang S, Lu C, Feng M, Jiang Y, Cao G, Zhang J, Liu C (2018) Micro-crack behavior of carbon fiber reinforced $\mathrm{Fe}_{3} \mathrm{O}_{4}$ /graphene oxide modified epoxy composites for cryogenic application. Compos A Appl Sci Manuf 108:12-22

3. Hung PY, Lau KT, Qiao K, Fox B, Hameed N (2019) Property enhancement of CFRP composites with different graphene oxide employment methods at a cryogenic temperature. Compos A Appl Sci Manuf 120:56-63

4. Miura M, Shindo Y, Takeda T, Narita F (2013) Cryogenic interlaminar fracture properties of woven glass/epoxy composite laminates under mixed-mode I/III loading conditions. Appl Compos Mater 20(4):587-599

5. Hussein A, Sarkar S, Lee K, Kim B (2017) Cryogenic fracture behavior of epoxy reinforced by a novel graphene oxide/poly (p-phenylenediamine) hybrid. Compos B Eng 129:133-142

6. Kara M, Kirici M, Tatar AC, Avci A (2018) Impact behavior of carbon fiber/epoxy composite tubes reinforced with multiwalled carbon nanotubes at cryogenic environment. Compos B Eng 145:145-154

7. Wu T, Liu Y, Li N, Huang GW, Qu CB, Xiao HM (2019) Cryogenic mechanical properties of epoxy resin toughened by hydroxylterminated polyurethane. Polym Testing 74:45-56

8. Li H, Chen G, Su H, Li D, Sun L, Yang J (2019) Effect of the stoichiometric ratio on the crosslinked network structure and cryogenic properties of epoxy resins cured at low temperature. Eur Polym J 112:792-798

9. Yang G, Zheng B, Yang JP, Xu GS, Fu SY (2008) Preparation and cryogenic mechanical properties of epoxy resins modified by poly (ethersulfone). J Polym Sci, Part A: Polym Chem 46(2):612-624

10. Gu J, Lv Z, Wu Y, Zhao R, Tian L, Zhang Q (2015) Enhanced thermal conductivity of SiCp/PS composites by electrospinning-hot press technique. Compos A Appl Sci Manuf 79:8-13

11. Wang Z, Li S, Wu Z (2015) The fabrication and properties of a graphite nanosheet/polystyrene composite based on graphite 
nanosheets treated with supercritical water. Compos Sci Technol 112:50-57

12. Yin L, Zhou X, Yu J, Wang H, Ran C (2016) Fabrication of a polymer composite with high thermal conductivity based on sintered silicon nitride foam. Compos A Appl Sci Manuf 90:626-632

13. Feng CP, Bai L, Bao RY, Liu ZY, Yang MB, Chen J, Yang W (2018) Electrically insulating POE/BN elastomeric composites with high through-plane thermal conductivity fabricated by tworoll milling and hot compression. Adv Composit Hybrid Mater 1(1):160-167

14. Yavuz H, Bai J (2018) Plasma polypyrrole coated hybrid composites with improved mechanical and electrical properties for aerospace applications. Appl Compos Mater 25(3):661-674

15. Moore AL, Shi L (2014) Emerging challenges and materials for thermal management of electronics. Mater Today 17(4):163-174

16. Mallik S, Ekere N, Best C, Bhatti R (2011) Investigation of thermal management materials for automotive electronic control units. Appl Therm Eng 31(2-3):355-362

17. Huang $X$, Jiang $P, X i e ~ L ~(2009)$ Ferroelectric polymer/silver nanocomposites with high dielectric constant and high thermal conductivity. Appl Phys Lett 95(24):242901

18. Dai S, Zhang T, Mo S, Cai Y, Yuan W, Ma T, Hu L, Wang B (2019) Study on preparation, thermal conductivity, and electrical insulation properties of epoxy/AIN. IEEE Trans Appl Supercond 29(2):1-6

19. Permal A, Devarajan M, Huong LH, Zahner T, Lacey D, Ibrahim K (2018) Enhanced thermal and mechanical properties of epoxy composites filled with hybrid filler system of aluminium nitride and boron nitride. Polym Compos 39(S3):E1372-E1380

20. Huang T, Zhang G, Gao Y (2019) A novel silver nanoparticledeposited aluminum oxide hybrids for epoxy composites with enhanced thermal conductivity and energy density. Compos Interfaces, pp 1-11

21. Wang F, Zeng $X$, Yao $Y$, Sun R, Xu J, Wong C-P (2016) Silver nanoparticle-deposited boron nitride nanosheets as fillers for polymeric composites with high thermal conductivity. Sci Rep 6:19394

22. Zhou T, Wang X, Mingyuan G, Liu X (2008) Study of the thermal conduction mechanism of nano-SiC/DGEBA/EMI-2, 4 composites. Polymer 49(21):4666-4672

23. Peng W, Huang X, Yu J, Jiang P, Liu W (2010) Electrical and thermophysical properties of epoxy/aluminum nitride nanocomposites: effects of nanoparticle surface modification. Compos A Appl Sci Manuf 41(9):1201-1209
24. Huang $X$, lizuka T, Jiang P, Ohki Y, Tanaka T (2012) Role of interface on the thermal conductivity of highly filled dielectric epoxy/AIN composites. J Phys Chem C 116(25):13629-13639

25. Ohashi M, Kawakami S, Yokogawa Y, Lai GC (2005) Spherical aluminum nitride fillers for heat-conducting plastic packages. J Am Ceram Soc 88(9):2615-2618

26. Yang G, Fu SY, Yang JP (2007) Preparation and mechanical properties of modified epoxy resins with flexible diamines. Polymer 48(1):302-310

27. Wu C-C, Chen Y-C, Yang C-F, Su C-C (2007) The dielectric properties of epoxy/AIN composites. J Eur Ceram Soc 27(13-15):3839-3842

28. Zhu BL, Wang J, Zheng H, Ma J, Wu J, Gan ZH, Liu J (2017) Thermal conductivity and dielectric properties of immiscible LDPE/ epoxy blend filled with hybrid filler consisting of HGM and nitride particle. J Alloys Compd 701:499-507

29. Huang X, Xie L, Jiang P, Wang G, Liu F (2009) Electrical, thermophysical and micromechanical properties of ethylene-vinyl acetate elastomer composites with surface modified $\mathrm{BaTiO} 3$ nanoparticles. J Phys D Appl Phys 42(24):245407

30. Qian R, Yu J, Xie L, Li Y, Jiang P (2013) Efficient thermal properties enhancement to hyperbranched aromatic polyamide grafted aluminum nitride in epoxy composites. Polym Adv Technol 24(3):348-356

31. Zhang J, Qi S (2014) Mechanical, thermal, and dielectric properties of aluminum nitride/glass fiber/epoxy resin composites. Polym Compos 35(2):381-385

32. Chikhi N, Fellahi S, Bakar M (2002) Modification of epoxy resin using reactive liquid (ATBN) rubber. Eur Polym J 38(2):251-264

33. Strzelec K, Leśniak E, Janowska G (2005) New polythiourethane hardeners for epoxy resins. Polym Int 54(9):1337-1344

34. Zhou W, Yu D (2010) Thermal and dielectric properties of the aluminum particle/epoxy resin composites. J Appl Polym Sci 118(6):3156-3166

35. Singha S, Thomas MJ (2008) Dielectric properties of epoxy nanocomposites. IEEE Trans Dielectr Electr Ins 15(1):12-23

Publisher's Note Springer Nature remains neutral with regard to jurisdictional claims in published maps and institutional affiliations. 